\title{
Sulforaphane suppresses the viability and metastasis, and promotes the apoptosis of bladder cancer cells by inhibiting the expression of FAT-1
}

\author{
FEI WANG ${ }^{1}$, PENGHUA LIU ${ }^{2}$, HEXIANG AN ${ }^{2}$ and YU ZHANG ${ }^{2}$ \\ ${ }^{1}$ Shenzhen Key Laboratory of Viral Oncology, Clinical Innovation and Research Center, Shenzhen Hospital of \\ Southern Medical University, Shenzhen, Guangdong 518101; ${ }^{2}$ Department of Urology, Baoan Central Hospital of Shenzhen, \\ The Fifth Affiliated Hospital of Shenzhen University, Shenzhen, Guangdong 518102, P.R. China
}

Received December 18, 2019; Accepted May 13, 2020

DOI: $10.3892 /$ ijmm.2020.4665

\begin{abstract}
FAT atypical cadherin 1 (FAT1) regulates complex mechanisms for the promotion of oncogenesis or the suppression of malignancies. Sulforaphane (SFN) has antioxidant and anti-tumor activities. The present study investigated the roles of SFN and FAT1 in bladder cancer (BC). The expression of FAT1 in BC cell lines and tissues was measured by western blot analysis and reverse transcription-quantitative PCR (RT-qPCR). The association between FAT1 expression and the 5-year survival rate of patients with $\mathrm{BC}$ was evaluated. The viability of and FAT1 expression in T24 and SW780 cells exposed to various concentrations of SFN were detected by MTT assay, and western blot analysis and RT-qPCR, respectively. Furthermore, the viability, migration, invasion and apoptosis of and FAT1 expression in BC cells subjected to FAT1 overexpression or knockdown, and with or without SFN stimulation, were examined. The results revealed that FAT1 expression in BC cells and tissues was increased, and patients with a high FAT-1 expression had a shorter 5-year survival time than those with a low FAT-1 expression. BC cell viability and FAT1 expression were suppressed by SFN in a concentration-dependent manner. The knockdown of FAT1 inhibited the viability, migration and invasion, and promoted the apoptosis of BC cells, whereas the overexpression of FAT1 produced opposite effects. In addition, cells exposed to SFN
\end{abstract}

Correspondence to: Dr Yu Zhang, Department of Urology, Baoan Central Hospital of Shenzhen, The Fifth Affiliated Hospital of Shenzhen University, 60 Leyuan Street, Xixiang, Baoan, Shenzhen, Guangdong 518102, P.R. China

E-mail: zyu_zhangyu@163.com

Abbreviations: FAT1, FAT atypical cadherin 1; SFN, sulforaphane; BC, bladder cancer; MEFs, mouse embryonic fibroblasts; RT-qPCR, reverse transcription-quantitative $\mathrm{PCR}$

Key words: FAT atypical cadherin 1, sulforaphane, bladder cancer, viability, metastasis exhibited a reduced viability, migration, invasion and an increased apoptosis, effects which were promoted by FAT1 knockdown; however, the overexpression of FAT1 blocked the above-mentioned effects of SFN on the cells. On the whole, the present study demonstrates that SFN suppresses the progression of BC by inhibiting the expression of FAT-1; thus, SFN may be used as a potential drug for the treatment of $\mathrm{BC}$.

\section{Introduction}

Bladder cancer (BC) is one of the leading causes of cancer-associated mortality worldwide, with a high incidence rate (1). Alterations in DNA repair pathwaya and signaling pathways, angiogenesis, genetic mutations and hypoxia all contribute to the development of BC (2). Surgical resection, immunotherapy, intravesical chemotherapy, and radical cystectomy with neoadjuvant chemotherapy have been used in the treatment of non-muscle-invasive or muscle-invasive BC (3). However, minimal improvements have been made in the cure rates and long-term survival of patients with $\mathrm{BC}$ over the past several decades (4).

Sulforaphane (SFN) is a natural isothiocyanate extracted from cruciferous plants. SFN has been used in the treatment of diabetic cardiomyopathy (5), angiogenesis (6) and cancer (7). The main pathway regulated by SFN is the Keap-1/nuclear factor erythroid 2-related factor 2 (Nrf2) pathway (8). Research has found that exposure to SF enables Nrf2 to escape from Keap1-dependent degradation, leading to the stabilization of Nrf2, the increased nuclear localization of Nrf2 and the activation of Nrf2-dependent cancer-protective genes $(9,10)$. SFN also regulates cell apoptosis. For instance, it has been shown that mouse embryonic fibroblasts (MEFs) treated with $40 \mathrm{mM}$ SF exhibit increased levels of Bax and Bak proteins at treatment for 4-8 h, although such effects are abolished in SF-treated MEFs derived from Bax/Bak double-knockout mutant mice (11). It has been found that JNK/MAPK is involved in SFN-mediated apoptosis $(12,13)$. Of note, SFN also inhibits apoptosis and cell cycle progression $(14,15)$. Thus, the complex function and mechanisms of SFN warrant further investigation. A previous study demonstrated that SFN suppressed the development and decreased the risk of 
developing BC. For instance, SFN combined with carbonic anhydrase acetazolamide inhibits tumor growth (16). SFN has also been shown to induce the apoptosis and cell cycle arrest of BC cells via the Nrf2 pathway and ROS-dependent pathway $(17,18)$. However, the mechanisms of action of SFN in BC are not yet fully understood.

FAT atypical cadherin 1 (FAT1) is an atypical cadherin, and plays a role in a variety of human cancers. More specifically, FAT1 suppresses epithelial-mesenchymal transition (EMT), which plays an important role in tumor metastasis (19). FAT1 knockdown in hypoxic glioblastoma cells has been shown to significantly decrease the expression levels of EMT/stemness markers (20). FAT1 however, has also been shown to inhibits the migration and invasion of esophageal squamous cell carcinoma cells (21). It has also been demonstrated that FAT1 significantly enhances the migratory and invasive properties of glioma cells (22). Moreover, protein-inactivating mutations in FAT1 have been detected in BC by whole-genome sequencing (23). However, the function of FAT1 in BC has not been identified to date.

Therefore, the present study aimed to investigate the roles of SFN and FAT1 in BC cells, in order to provide insight into the mechanisms underlying the role of SFN in BC.

\section{Materials and methods}

Sample collection. In the present study, 85 bladder cancer tissues and 27 adjacent normal tissues were collected from patients with BC who attended the Shenzhen Hospital of Southern Medical University from 2010 to 2014 for treatment. All the tissues were stored at $-80^{\circ} \mathrm{C}$. The present study was reviewed and approved by the Committee for Ethical Review of Research at Shenzhen Hospital of Southern Medical University, and all the patients signed an informed consent. The relative expression of FAT1 (high or low) was determined according to the median expression of FAT1 in BC tissues.

Cell culture and treatment. The normal bladder cell line, SV-HUC-1 (CRL-9520), and the BC cell lines, 5637 (HTB-9), T24 (HTB-4), J82 (HTB-1), SW780 (CRL-2169) and UM-UC-3 (CRL-1749), were purchased from the American Type Culture Collection (ATCC). The BC cell lines, 5637, J82 and UM-UC-3, were cultured in MEM (12492013, Gibco; Thermo Fisher Scientific, Inc.); SV-HUC-1 cells were cultured in Ham's F-12K medium (21127030, Gibco; Thermo Fisher Scientific, Inc.); T24 cells were grown in McCoy's medium (16600082, Gibco; Thermo Fisher Scientific, Inc.); SW780 cells were grown in RPMI-1640 medium (31870082, Gibco; Thermo Fisher Scientific, Inc.). All the media were supplemented with 10\% FBS (10099141, Gibco; Thermo Fisher Scientific, Inc.), $100 \mathrm{units} / \mathrm{ml}$ penicillin and $100 \mu \mathrm{g} / \mathrm{ml}$ streptomycin (15140163, Gibco; Thermo Fisher Scientific, Inc.). The cells were grown at $37^{\circ} \mathrm{C}$ with $5 \% \mathrm{CO}_{2}$.

The T24 and SW780 cells were separately cultured in a 24 -well plates at a density of $3 \times 10^{5}(\mathrm{cell} / \mathrm{ml})$ for $24 \mathrm{~h}$. For the silencing FAT1 siRNA targeting FAT1 were used. the sequences of the siRNAs were obtained from GenePharma and demonstrated as follows: siFAT1 sense, 5'-GGGCCAGUC AAGUUUGAAA-3' and antisense, 5'-CCCGGUCAGUUC AAACUUU-3'); and siNC as the siRNA control sense, 5'-UUC
UCCGAACGUGUCACGUTT-3' and antisense, 5'-ACGUGA CACGUUCGGAGAATT-3'. The empty pcDNA3.1 plasmid (NC) and FAT1-pcDNA3.1 plasmid (FAT1) were purchased from Sigma-Aldrich; Merck KGaA. The medium in the 24-well plates was then replaced after $24 \mathrm{~h}$, and the T24 and SW780 cells were separately transfected with 10 pmol siFAT1, siNC, NC, or FAT1 using Lipofectamine 2000 transfection reagent (Thermo Fisher Scientific, Inc.). The cells were harvested $24 \mathrm{~h}$ following transfection and used in subsequent experiments. To examine the effects of SFN (Sigma-Aldrich; Merck KGaA) on the BC cells, the T24 and SW780 cells were incubated with SFN $(0,10,20,40$ and $80 \mu \mathrm{mol} / \mathrm{l})$ for $24 \mathrm{~h}$ at $37^{\circ} \mathrm{C}$. The T2 4 and SW780 cells transfected with siNC, siFAT1, NC or FAT1 overexpression plasmid were incubated with SFN $(20 \mu \mathrm{mol} / \mathrm{l})$ for $24 \mathrm{~h}$ at $37^{\circ} \mathrm{C}$.

Western blot analysis. The tissues were homogenized by bead milling for approximately $5 \mathrm{~min}$ at $4^{\circ} \mathrm{C}$, and the cells were treated with lysis buffer for $30 \mathrm{~min}$ on ice. Proteins were then collected by centrifugation at $1,000 \mathrm{x} \mathrm{g}$, at $4^{\circ} \mathrm{C}$ for $30 \mathrm{~min}$. Subsequently, proteins (approximately $50 \mu \mathrm{g}$ ) were denatured, separated on $12 \%$ SDS/PAGE gels, and then transfected onto a PVDF membrane (LC2002, Invitrogen; Thermo Fisher Scientific, Inc.). This was followed by blocking of the membranes with 5\% fat-free milk. Primary antibodies to FAT-1 (1:2,000, ab190242, Abcam) and GAPDH (1:2,000, ab8245, Abcam) were then separately incubated with the membrane for $>8 \mathrm{~h}$ at $4^{\circ} \mathrm{C}$. Subsequently, anti-rabbit IgG antibody (1:5,000, 7074, Cell Signaling Technology, Inc.) and anti-mouse IgG antibody (31430, Thermo Fisher Scientific, Inc.) were incubated with the membrane at room temperature for $2 \mathrm{~h}$. Finally, the protein signal of the membrane was detected using ECL Chemiluminescent Substrate (WP20005, Thermo Fisher Scientific, Inc.) and analyzed using an ImageQuant ECL Imager (28-9605-63, GE Healthcare).

Reverse transcription-quantitative PCR (RT-qPCR). Tissues were homogenized by bead milling with TRIzol reagent for approximately $5 \mathrm{~min}$ at $4^{\circ} \mathrm{C}$, and the cells were treated with lysis buffer for $30 \mathrm{sec}$ on ice. RNA was then isolated from the tissues and cells at $4^{\circ} \mathrm{C}$ using chloroform and isopropanol. Subsequently, $1 \mu \mathrm{g}$ RNA was used for reverse transcription with the PrimeScript ${ }^{\mathrm{TM}}$ II 1st Strand cDNA Synthesis kit (6210B, Takara Bio, Inc.). SYBR ${ }^{\circledR}$-Green PCR Master Mix (4312704, ABI) and Bio-Rad CFX 96 Touch Real-Time PCR Detection System (1855196, Bio-Rad Laboratories, Inc.) were used for qPCR analysis. The parameters were set up as follows: $95^{\circ} \mathrm{C}$ for $5 \mathrm{~min}, 40$ cycles of $95^{\circ} \mathrm{C}$ for $15 \mathrm{sec}, 60^{\circ} \mathrm{C}$ for $30 \mathrm{sec}$, and $70^{\circ} \mathrm{C}$ for $10 \mathrm{sec}$. GAPDH served as an internal control, and the relative gene expression levels were calculated using the $2^{-\Delta \Delta \mathrm{Cq}}$ method (24). The sequences of the primers used were as follows: FAT-1 forward, 5'-CATCCTGTCAAG ATGGGTGTTT-3' and reverse, 5'-TCCGAGAATGTACTC TTCAGCTT-3'; and GAPDH forward, 5'-GGAGCGAGATCC CTCCAAAAT-3' and reverse, 5'-GGCTGTTGTCATACT TCTCATGG-3'.

MTT assay. Briefly, cells (4,000 cells/well) were seeded in a 96-well plate. Following culture for $48 \mathrm{~h}$, the medium was removed and $10 \mu \mathrm{l}$ MTT solution mixed with $110 \mu \mathrm{l}$ fresh 

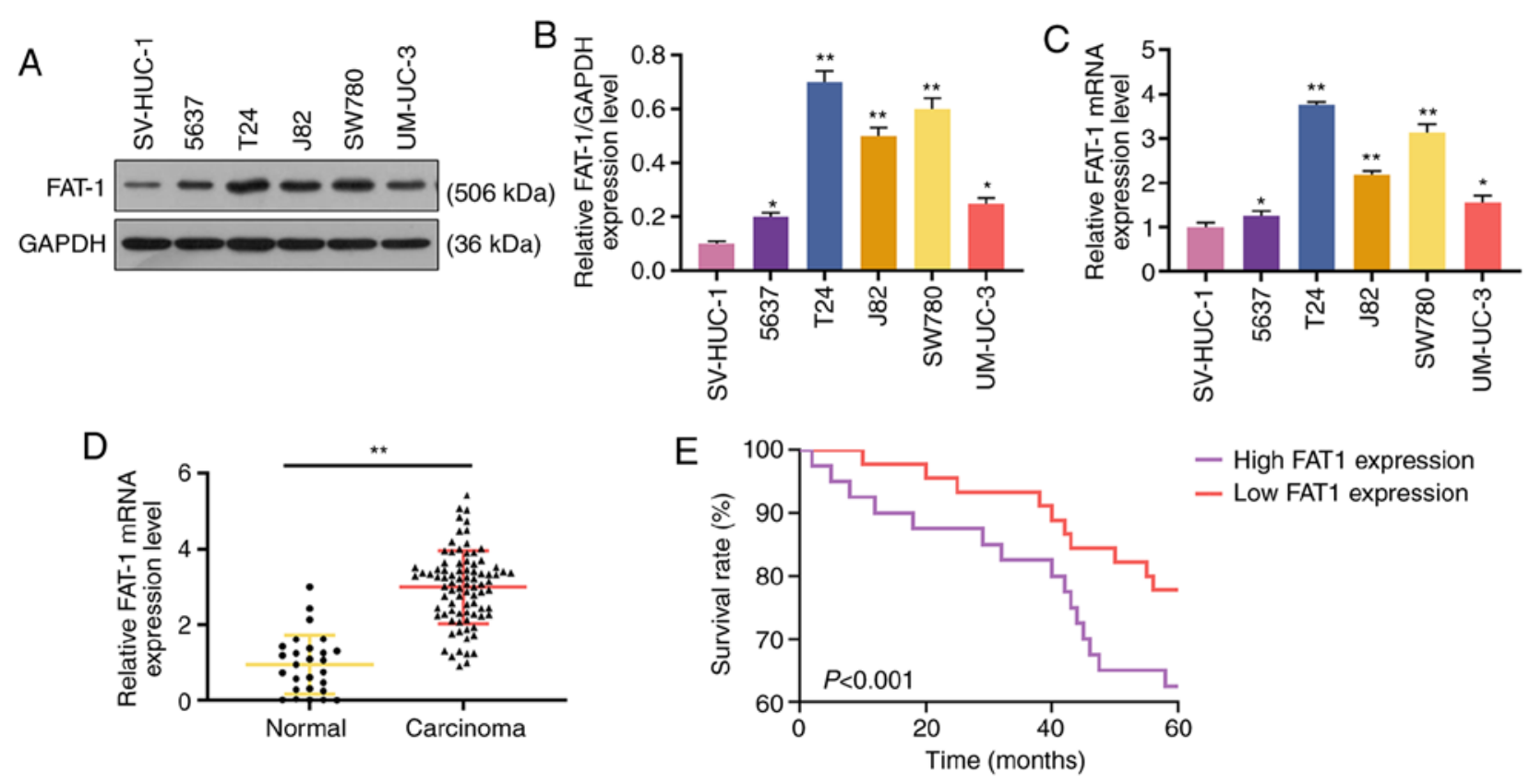

Figure 1. FAT-1 expression is upregulated in BC and is associated with a lower survival rate of patients with BC. (A-C) Western blot analysis and RT-qPCR of FAT-1 expression in BC cell lines. ${ }^{*}<0.05,{ }^{* *} \mathrm{P}<0.001$ vs. SV-HUC-1 cells. (D) RT-qPCR analysis of FAT-1 expression in 85 BC tissues and 27 adjacent normal tissues. ${ }^{* *} \mathrm{P}<0.001$ vs. normal tissues. (E) The 5-year survival rate of patients with high expression or low expression of FAT-1. BC, bladder cancer; FAT-1, FAT atypical cadherin 1.

medium were added to each well. Following incubation at $37^{\circ} \mathrm{C}$ for $4 \mathrm{~h}$, the medium was removed, and $150 \mu \mathrm{l}$ DMSO was added to each well. The absorbance value at $570 \mathrm{~nm}$ was then detected using a microplate reader (PLUS 384, Molecular Devices, LLC).

Wound-healing assay. A scratch was generated using a $10 \mu \mathrm{l}$ pipette tip when cells in a 6 -well plate reached $80 \%$ confluence. Subsequently, the cells were cultured in serum-free medium for $48 \mathrm{~h}$. The scratch area was observed under a microscope (TS100, Nikon Corp.) at 0 and $48 \mathrm{~h}$. In total, 10 fields of the scratch area of each group were selected to be observed under a microscope (TS100, Nikon Corp.) for statistical analysis conducted by SPSS 19.0 software (SPSS, Inc.).

Transwell assay. The upper chamber of a Transwell plate (3428, Corning, Inc.) was coated with Matrigel. The cells $\left(2 \times 10^{3}\right.$ cells/well) were added to the upper chamber with serum-free medium. Moreover, $600 \mu 1$ normal medium with $20 \%$ FBS was added to the lower chamber. Following incubation at $37^{\circ} \mathrm{C}$ for $24 \mathrm{~h}$, the invaded cells were fixed with methanol and stained with $0.1 \%$ crystal violet (R40052, Thermo Fisher Scientific, Inc.) at room temperature for approximately $30 \mathrm{~min}$. Subsequently, 10 fields were randomly selected and the numbers of invaded cells were counted under a microscope (TS100, Nikon). The assay was independently repeated in triplicate, and the statistical analysis was conducted using SPSS 19.0 software (SPSS, Inc.).

Flow cytometry. The Annexin-V kit (70-AP101-100-AVF, MultiSciences) was used to detect cell apoptosis according to the instructions provided with the kit. In brief, the cells $\left(2 \times 10^{5}\right.$ cells) were cultured in a 6 -well plate for $24 \mathrm{~h}$. The cells were then collected by trypsinization at $4^{\circ} \mathrm{C}$ for $2 \mathrm{~min}$ and centrifugation at $450 \mathrm{xg}, 4^{\circ} \mathrm{C}$ for $5 \mathrm{~min}$, and then washed with pre-cold PBS. Subsequently, the cells were incubated with $300 \mu 1$ binding buffer, supplemented with $5 \mu 1$ Annexin V-FITC and incubated at room temperature for $20 \mathrm{~min}$. PI $(5 \mu \mathrm{l})$ was then incubated with the cells at $4^{\circ} \mathrm{C}$ for $15 \mathrm{~min}$ to stain the nuclei. Finally, $200 \mu 1$ binding buffer were incubated with the cells at room temperature for $5 \mathrm{~min}$. Cell apoptosis was detected using a FACSCalibur flow cytometer (342973, BD Biosciences). The BD FACSCanto ${ }^{\mathrm{TM}}$ system software v2.4 (646602, BD Biosciences) was used for further analysis.

Statistical analysis. Data are presented as the means \pm SD. One-way analysis of variance followed by Tukey's multiple-comparison test was used to analyze the statistical differences between groups using SPSS 19.0 software (SPSS, Inc.). Kaplan-Meier analysis was applied for survival analysis in the study, and the log-rank test was used to calculate the $\mathrm{P}$-values. $\mathrm{P}<0.05$ was considered to indicate a statistically significant difference.

\section{Results}

FAT-1 expression is upregulated in BC and is associated with a lower survival rate of patients with $B C$. Western blot analysis and RT-qPCR were performed to analyze the expression of FAT-1 in BC cells and tissues to explore the role of FAT-1 in BC. The results revealed that FAT-1 was significantly upregulated in $\mathrm{BC}$ cells and tissues $(\mathrm{P}<0.05$ or $\mathrm{P}<0.001$, Fig. 1A-D). In addition, patients with a relatively high expression (compared with median expression) of FAT-1 exhibited a shorter 5-year survival than those with a relatively low expression (compared with median expression) of FAT-1 ( $\mathrm{P}<0.001$, Fig. 1E). As the levels of FAT-1 were relatively higher in the T24 and SW780 BC cells, these two cell lines were therefore used for further analysis. 
A

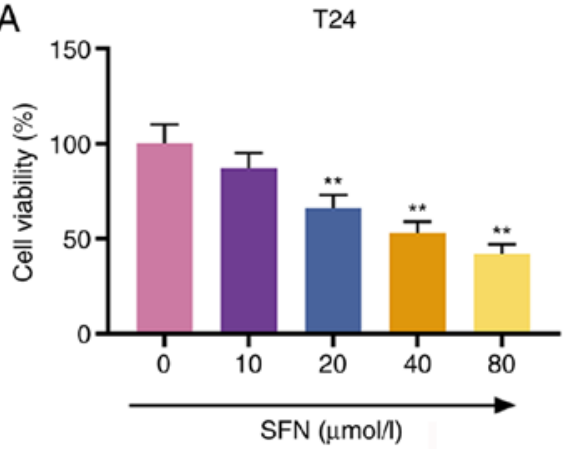

C

T24

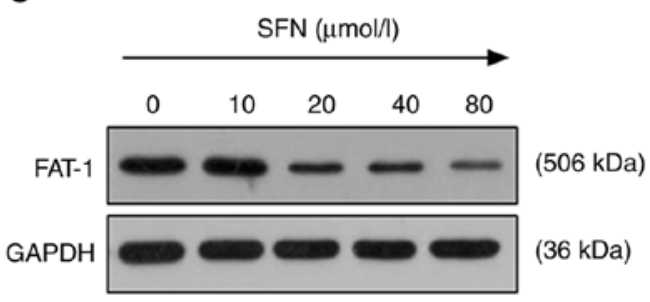

E

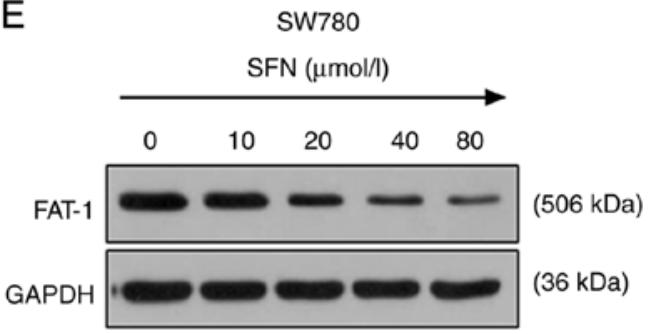

B

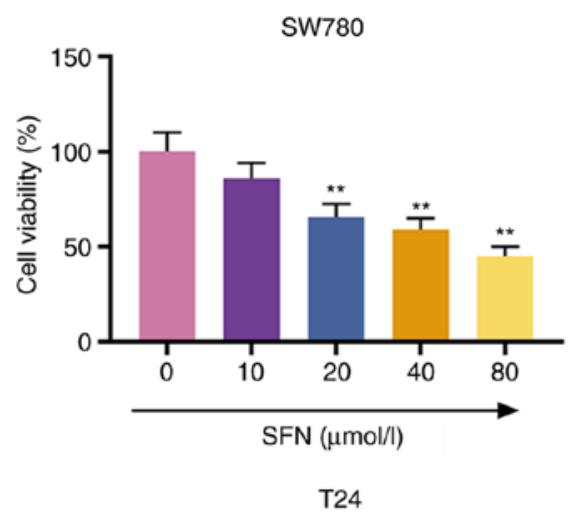

D

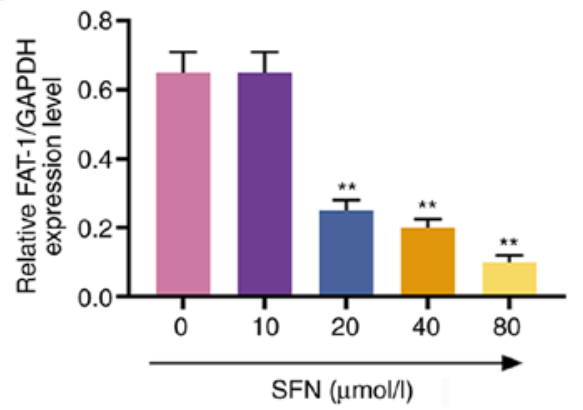

$\mathrm{F}$

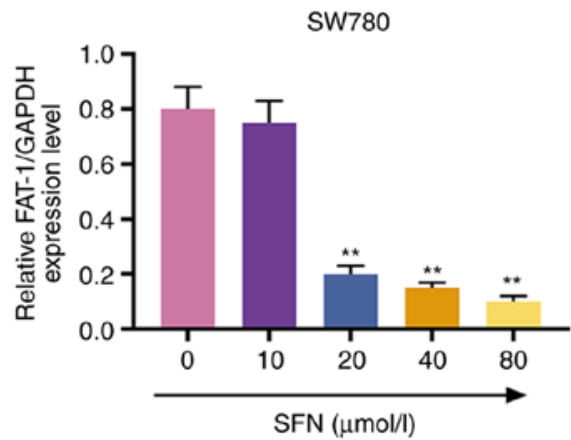

Figure 2. SFN inhibits the viability of and the expression of FAT-1 in BC cells. (A and B) Viability of T24 and SW780 cells exposed to various concentrations of SFN were detected by MTT assay. (C-F) Western blot analysis of FAT-1 expression in T24 and SW780 cells exposed to various concentrations of SFN ${ }^{* *} \mathrm{P}<0.001$ vs. o $\mu \mathrm{mol} / 1$. GAPDH was used as an internal control. BC, bladder cancer; FAT-1, FAT atypical cadherin 1; SFN, sulforaphane.

SFN inhibits the viability and the expression of FAT-1 in BC cells. To examine the effects of SFN on the development of BC cells, T24 and SW780 BC cells were exposed to SFN at concentrations of $0,10,20,40$ and $80 \mu \mathrm{mol} / 1$ for $24 \mathrm{~h}$. Cell viability was measured by MTT assay. The results demonstrated that SFN at 20,40 and $80 \mu \mathrm{mol} / 1$ exerted a suppressive effect on the viability of the T24 and SW780 cells $(\mathrm{P}<0.001$, Fig. 2A and B). It was also found that FAT-1 expression in the T24 and SW780 cells exposed to SFN at 20, 40 and $80 \mu \mathrm{mol} / \mathrm{l}(\mathrm{P}<0.001$, Fig. $2 \mathrm{C}-\mathrm{F})$ was markedly decreased. SFN at $20 \mu \mathrm{mol} / 1$ was used in subsequent experiments.

SFN inhibits the viability, migration and invasion of $B C$ cells by decreasing the expression of FAT-1. To explore the function of FAT-1 and SFN in BC, T24 and SW780 cells were transfected with siFAT-1 (P<0.001, Fig. 3A-F). MTT assay revealed that the knockdown of FAT-1 inhibited the viability of the T24 and SW780 cells ( $\mathrm{P}<0.001$, Fig. 3G and H). Compared with the results shown in Fig. 2, it could be observed that SFN suppressed the viability, and the migratory and invasive abilities of the two cell lines, while SFN combined with siFAT-1 enhanced these effects on the above-mentioned cell behaviors $(\mathrm{P}<0.001$, Fig. 4). Although siFAT-1 only slightly decreased viability, the difference was statistically significant.

SFN promotes $B C$ cell apoptosis by inhibiting the expression of FAT-1. Subsequently, the apoptosis and FAT-1 expression in T24 and SW780 cells transfected with siNC, siFAT-1, treated with SFN, or co-treated with siFAT-1 and SFN were detected. The results revealed that SFN alone or siFAT-1 induced cell apoptosis, and inhibited the expression of FAT-1, as compared with the siNC group. siFAT-1 combined with SFN treatment enhanced cell apoptosis and markedly inhibited the expression of FAT-1 (P<0.001, Fig. 5).

FAT-1 overexpression reverses the effects of SFN on viability, metastasis and apoptosis of T24 and SW780 cells. To further confirm the association between SFN and FAT-1, the FAT-1 overexpression plasmid, pc-FAT1, was transfected into T24 and SW780 cells treated with or without SFN. As shown in Fig. 6, FAT-1 was successfully overexpressed in the T24 and SW780 cells $(\mathrm{P}<0.001)$. Subsequently, cell behaviors were examined, 


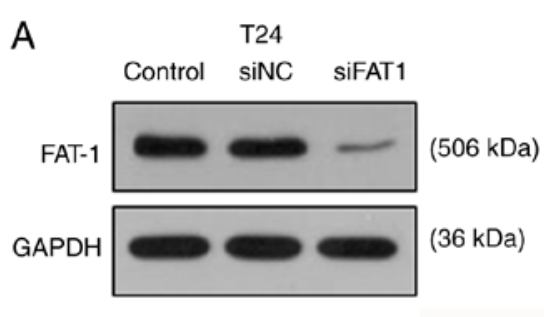

B T24

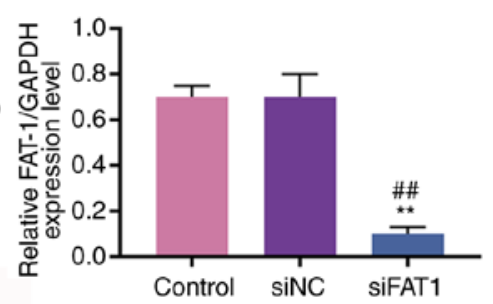

E $\quad$ SW780

D

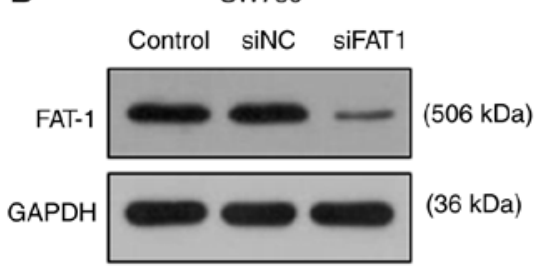

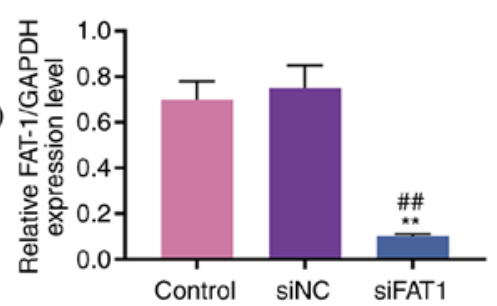

C

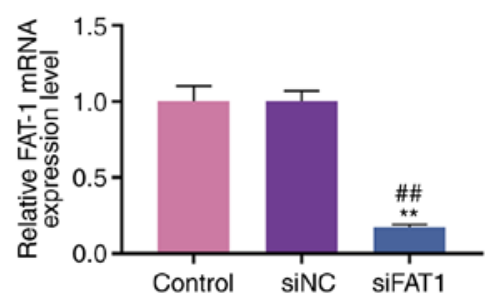

F

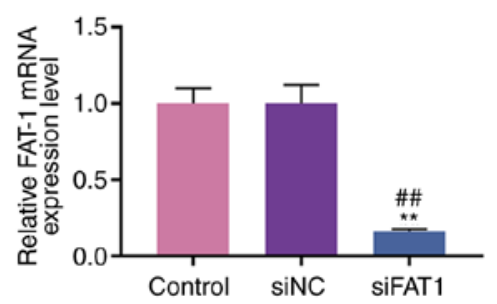

G

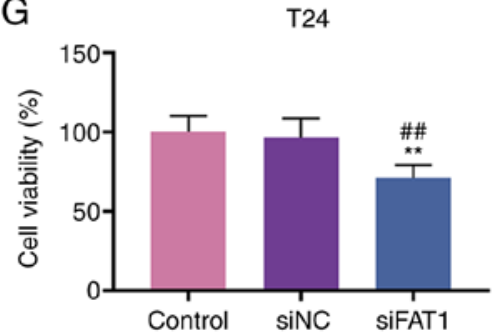

$\mathrm{H}$

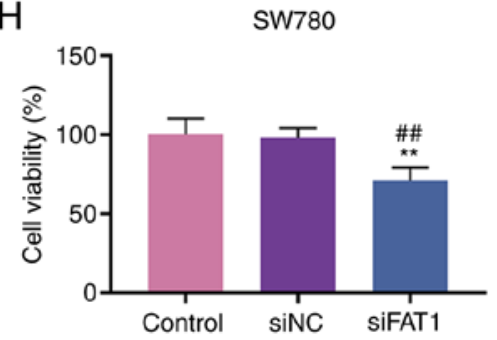

Figure 3. Silencing of FAT-1 suppresses the viability of BC cells. (A-F) The efficiency of FAT-1 knockdown in T24 and SW780 cells was detected by western blot analysis and RT-qPCR. (G and H) Viability of T24 and SW780 cells were detected by MTT assay following transfection with blank (control), siNC or siFAT-1. ${ }^{* *} \mathrm{P}<0.001$ vs. control. ${ }^{\# \#} \mathrm{P}<0.001$ vs. siNC. BC, bladder cancer; FAT-1, FAT atypical cadherin 1; SFN, sulforaphane.

and the results revealed that FAT-1 overexpression enhanced the viability, migration and invasion, and decreased the cell apoptotic rate of the T24 and SW780 cells. However, SFN counteracted the promoting effects of FAT-1 overexpression on the proliferation, migration and invasion, and the suppressive effects on the apoptosis of the two cell lines $(\mathrm{P}<0.001$, Figs. 7 and 8A-D). The change in FAT-1 expression was then detected by western blot analysis and RT-qPCR. It was observed that SFN blocked the expression of FAT-1 to a modest, yet significant degree, even in comparison with pc-FAT-1 overexpression in T24 and SW780 cells ( $\mathrm{P}<0.001$, Fig. 8E-J).

\section{Discussion}

The overgrowth and metastasis of tumor cells are the major cause of cancer recurrence and associated mortality (25). Therefore, effective antitumor therapy should not only focus only on the inhibition of tumor cell growth, but also on the prevention of metastasis. It has been demonstrated that SFN exerts anti-carcinogenic effects on various types of cancer, such as ovarian cancer (26), gastric cancer (27), lung cancer (28) and bladder cancer (18). However, the molecular mechanisms of action of SFN in BC remain unknown. The present study found that SFN exerted antitumor effects through the suppression of the growth, migration and invasion, and the induction of apoptosis of BC cells. Moreover, these effects of SFN were largely mediated by the inhibition of the expression of FAT1.
FAT1 is considered a tumor suppressor in various types of cancer. For instance, a low expression of FAT1 is frequently observed in head and neck squamous cell carcinoma and oral squamous cell carcinoma $(29,30)$; antibody targeting FAT1 could possibly be a novel therapeutic strategy for the treatment of colorectal cancer (31); however, FAT1 is upregulated in grade IV glioma cells, and is an upstream regulator of oncogenic and inflammatory pathways (22). Moreover, glioblastoma cells in which FAT1 is knocked down are more susceptible to death receptor-mediated apoptosis (32). In BC, protein-inactivating mutations in FAT1 have been previously identified (23). However, the present study found that FAT1 was upregulated in BC and was associated with a low 5-year survival rate, suggesting that FAT1 may be involved in the progression and prognosis of BC. Further experiments indicated that the silencing of FAT1 suppressed the viability and metastasis of T24 and SW780 cells, whereas the overexpression of FAT1 produced opposite effects on the two cell lines. Rescue assays also demonstrated that the apoptosis of the two cell lines was enhanced by the knockdown of FAT1 in combination with SFN treatment, whereas it was inhibited by the overexpression of FAT1 combined with SFN stimulation. Thus, the current findings indicate that FAT1 may function as an oncogenic driver in BC.

SFN is a natural product, and previous studies have demonstrated that SFN exerts an antitumor effect on BC. For instance, SFN has been shown to inhibit cell viability and induce cell apoptosis in a dose-dependent manner, and 

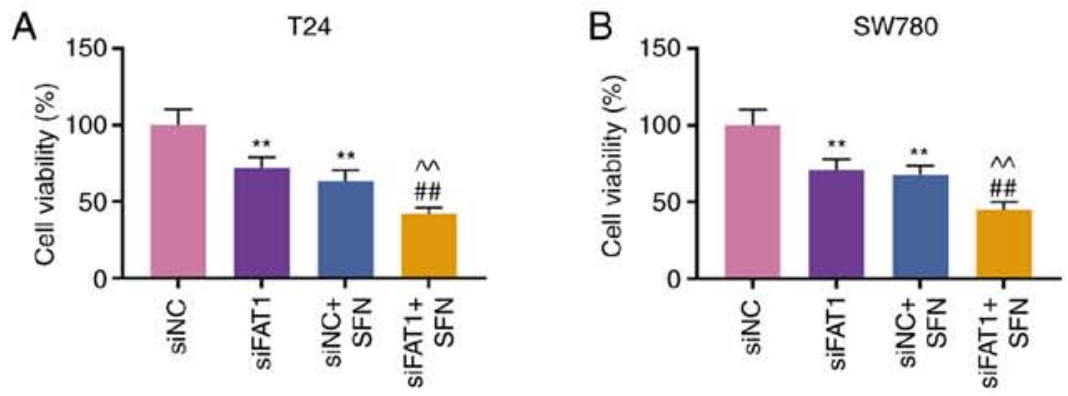

C
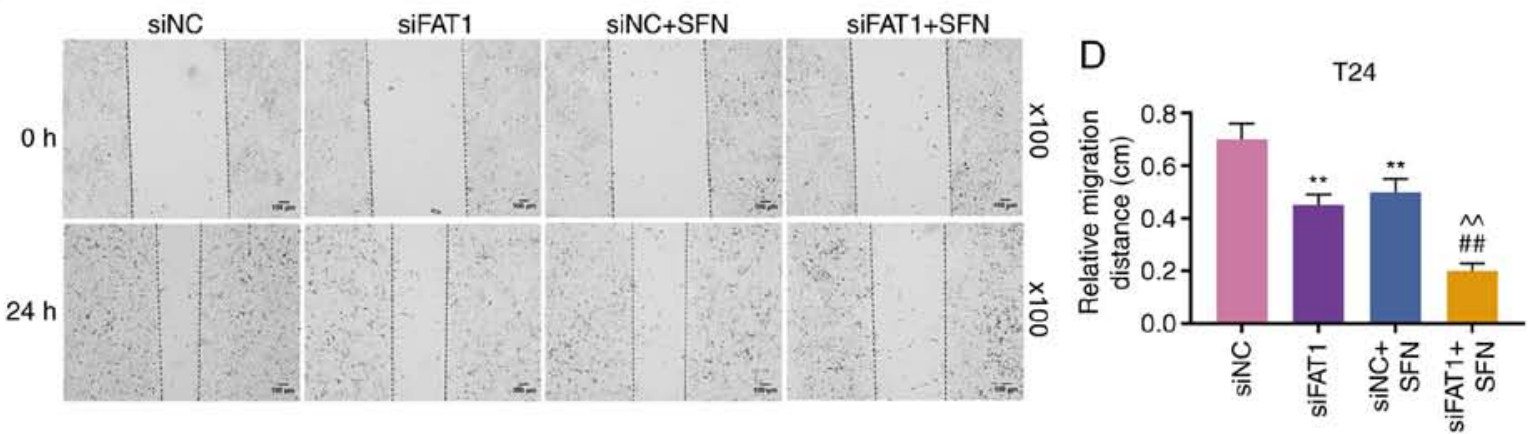

E

SW780
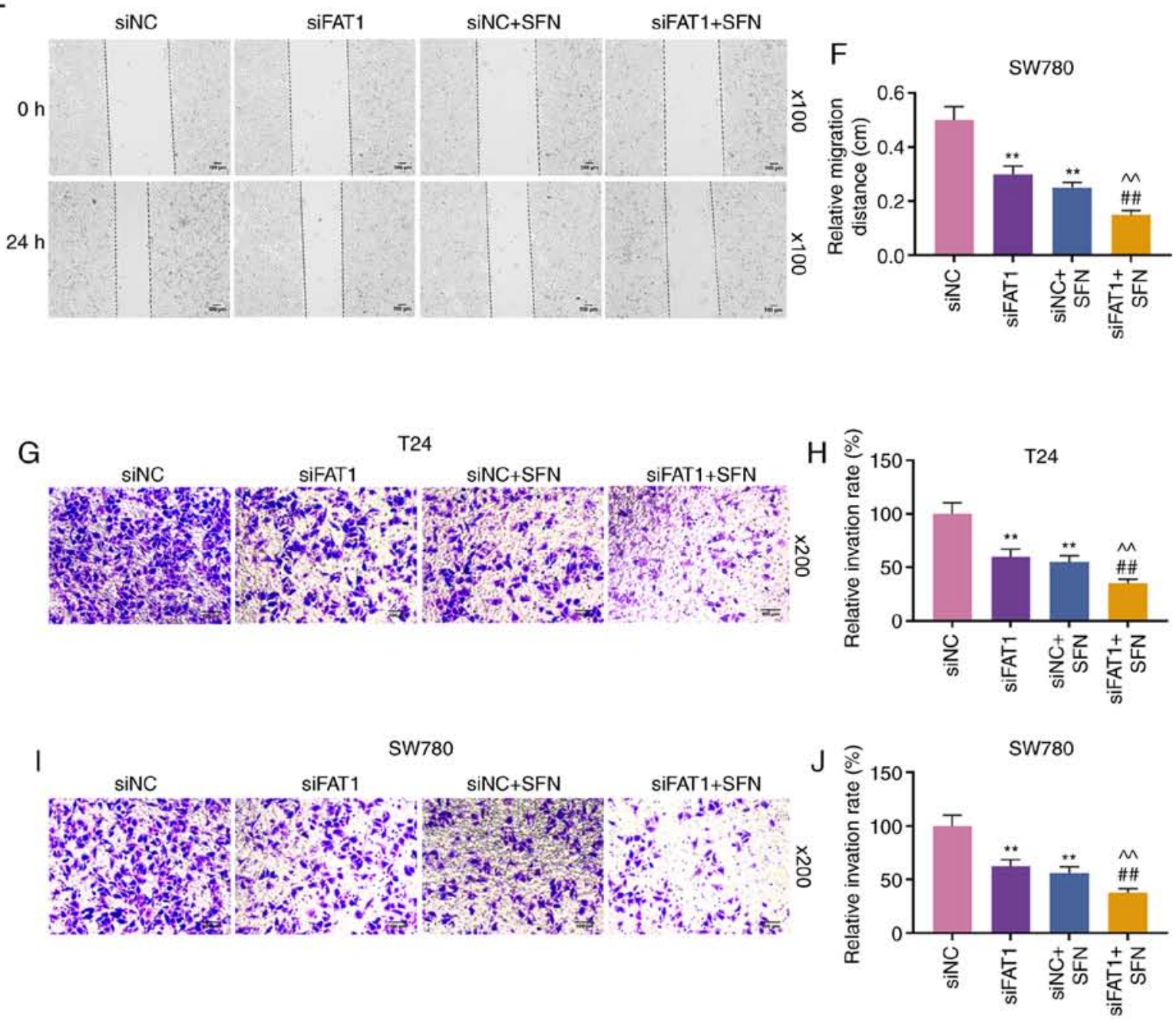

Figure 4. SFN inhibits the viability, migration and invasion of BC cells by inhibiting the expression of FAT-1. (A and B) Viability of T24 and SW780 cells detected by MTT assay. (C-F) Migratory abilities of T24 and SW780 cells were detected by wound-healing assay. Magnification, $x 100 ;$ scale bar, $100 \mu \mathrm{m}$ (G-J) Invasive abilities of T24 and SW780 cells were detected by wound-healing assay. Magnification, $\mathrm{x} 200$; scale bar, $100 \mu \mathrm{m} .{ }^{* * *} \mathrm{P}<0.001 \mathrm{vs}$. siNC. ${ }^{\# /} \mathrm{P}<0.001$ vs. siNC + SFN. ^ ${ }^{\wedge}$ P $<0.001<0.001$ vs. si FAT-1. BC, bladder cancer; FAT-1, FAT atypical cadherin 1 ; SFN, sulforaphane. 
A

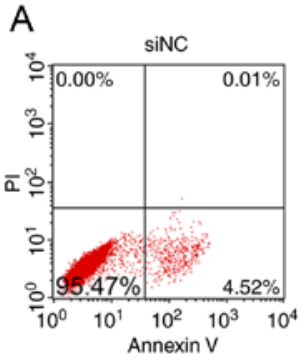

C

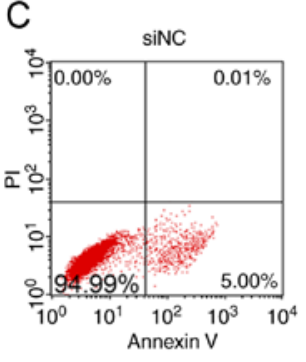

D

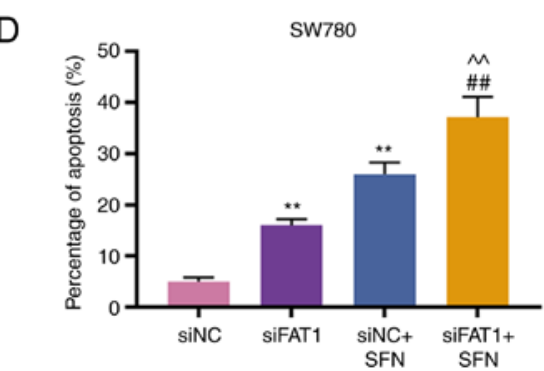

T24
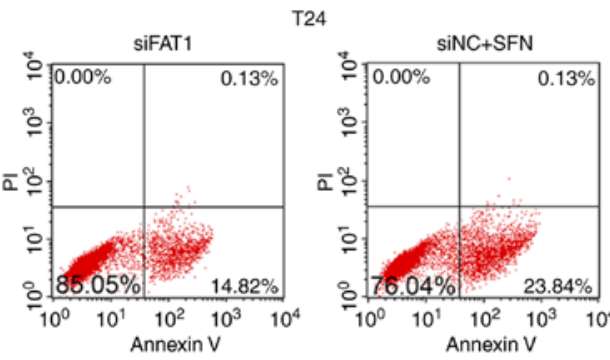

B
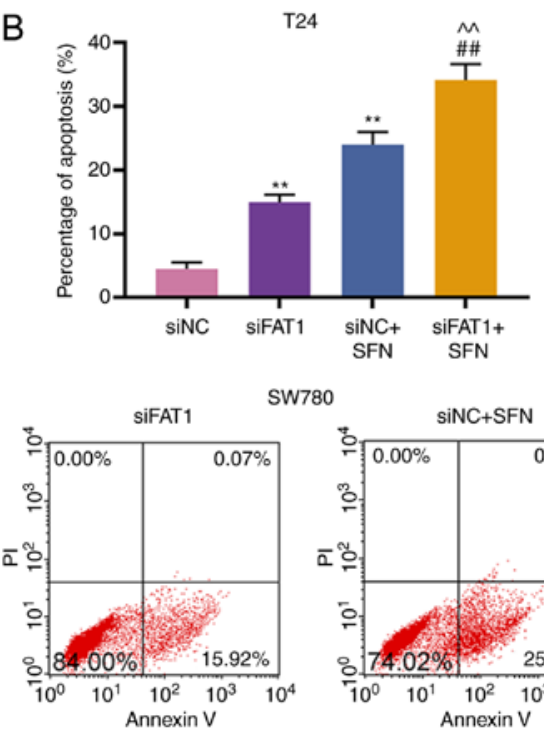

W780

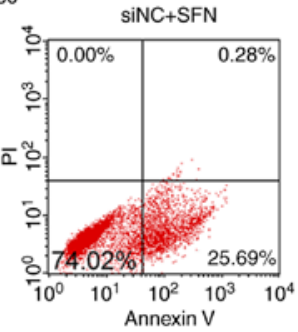

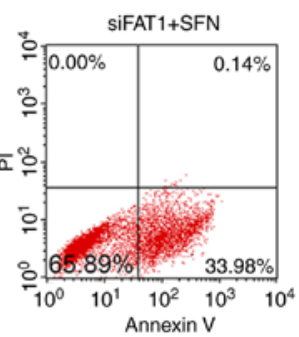

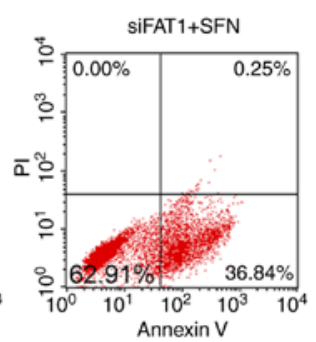

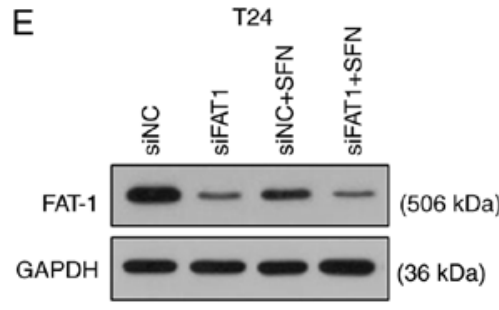

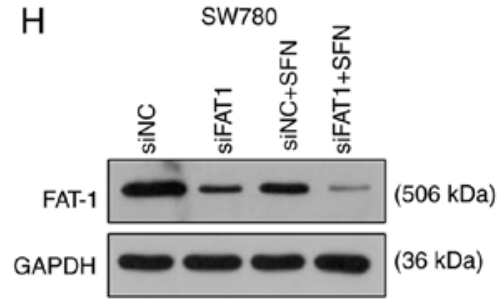

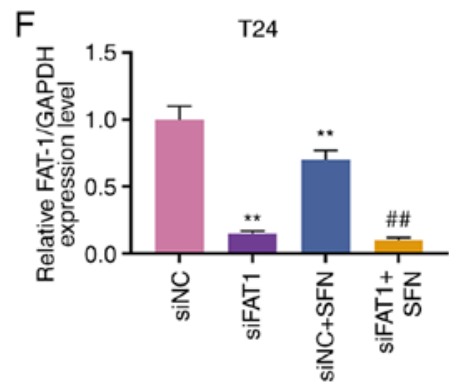

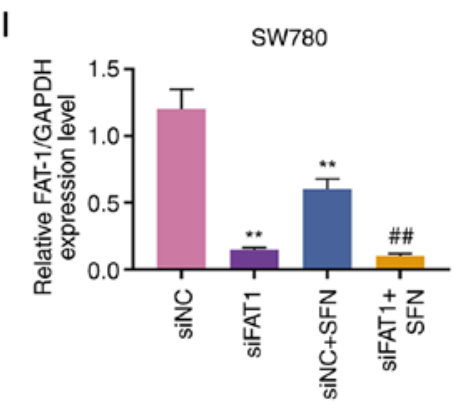

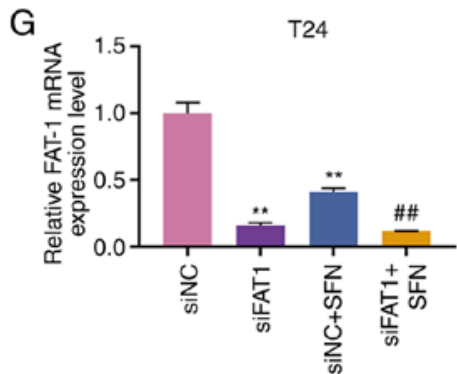

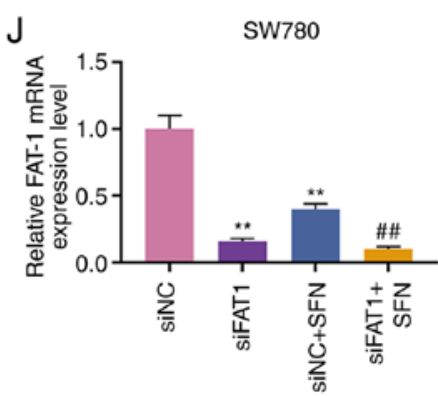

Figure 5. SFN promotes apoptosis by inhibiting the expression of FAT-1. (A-D) Apoptosis of T24 and SW780 cells was measured by flow cytometry. (E-J) The expression of FAT-1 was detected by western blot analysis and RT-qPCR was regulated by siFAT-1 and SFN stimulation in T24 and SW780 cells. ${ }^{* *}$ P $<0.001$ vs. siNC. ${ }^{\#} \mathrm{P}<0.001$ vs. siNC + SFN. ${ }^{\wedge} \mathrm{P}<0.001<0.001$ vs. si FAT-1. BC, bladder cancer; FAT-1, FAT atypical cadherin 1 ; SFN, sulforaphane. 
A
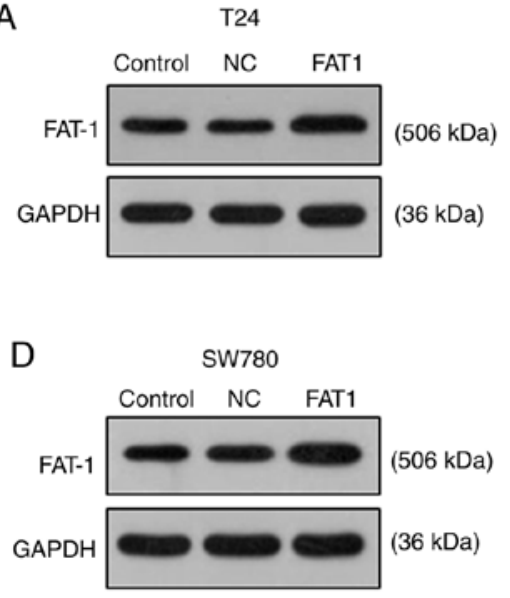

B

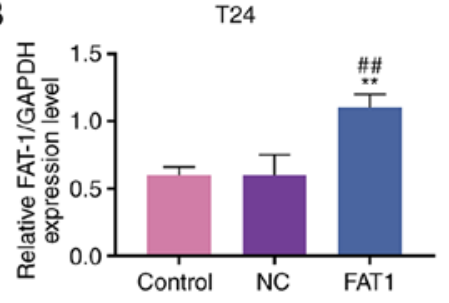

$\mathrm{E}$

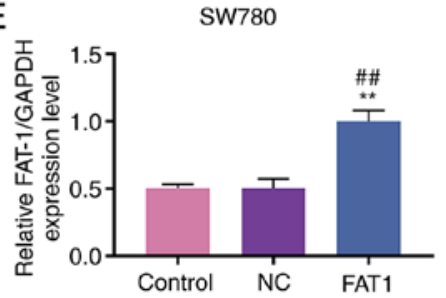

C

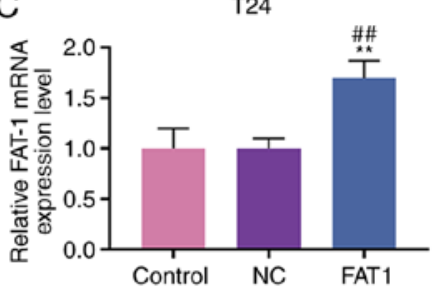

$\mathrm{F}$

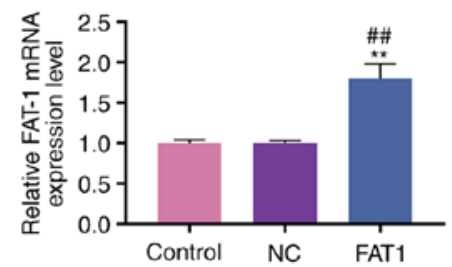

Figure 6. efficiency of FAT-1 overexpression in T24 and SW780 cells. (A-C) Efficiency of FAT-1 overexpression in T24 cells was detected by western blot analysis and RT-qPCR. (D-F) Efficiency of FAT-1 overexpression in SW780 cells was detected by western blot analysis and RT-qPCR. "** $\mathrm{P}<0.001$ vs. control. ${ }^{\# \prime} \mathrm{P}<0.001$ vs. NC. BC, bladder cancer; FAT-1, FAT atypical cadherin 1; SFN, sulforaphane.
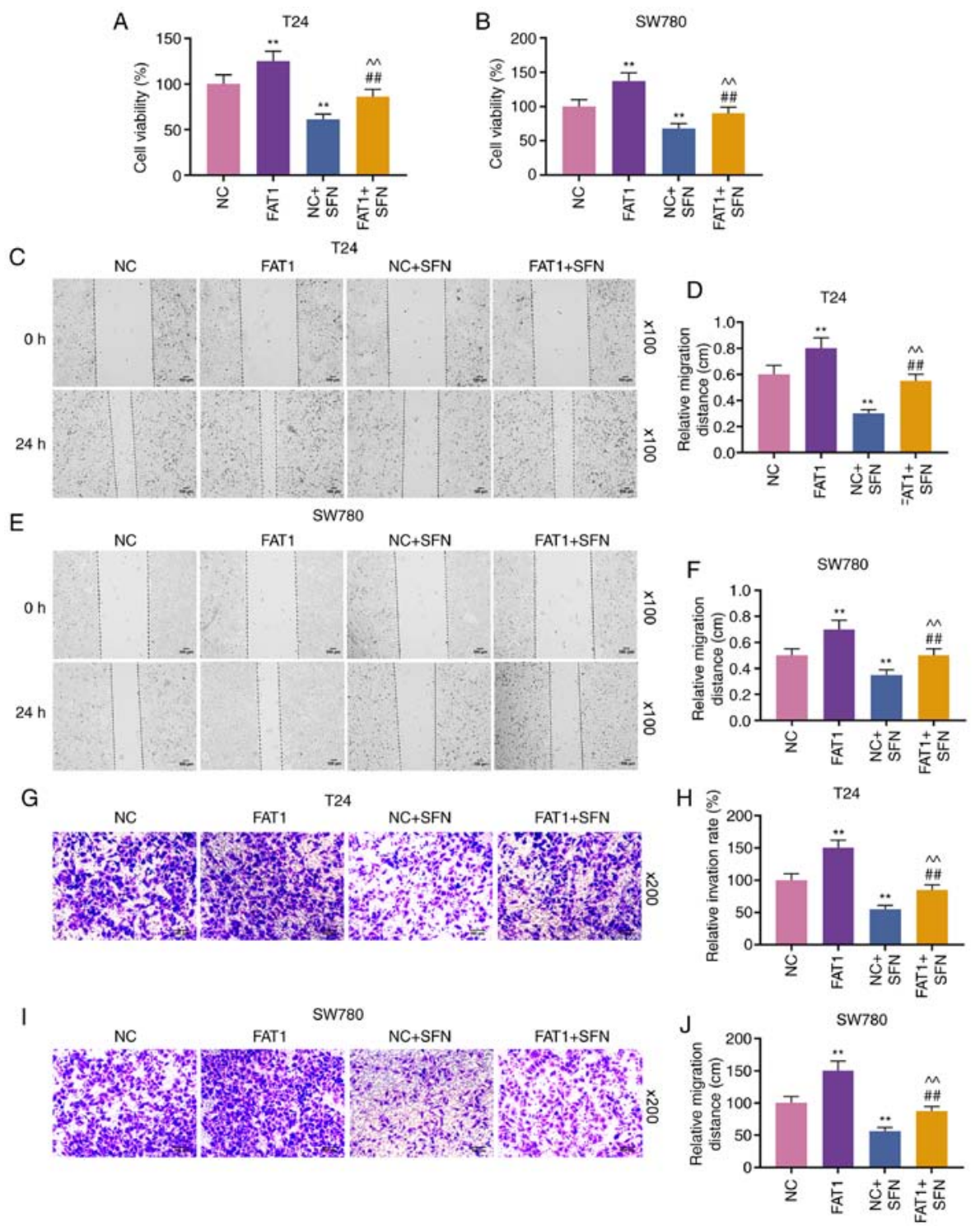

Figure 7. FAT-1 overexpression reverses the effects of SFN on the viability and metastasis of T24 and SW780 cells. (A and B) Viabilities of T24 and SW780 cells were detected by MTT assay. (C-F) Migratory abilities of T24 and SW780 cells were detected by wound-healing assay. Magnification, x100; scale bar, $100 \mu \mathrm{m}$. (G-J) Invasive abilities of T24 and SW780 cells were detected by wound-healing assay. Magnification, x200; scale bar, $100 \mu \mathrm{m}$. ${ }^{* *} \mathrm{P}<0.001 \mathrm{vs}$. NC. ${ }^{\#} \mathrm{P}<0.001$ vs. NC + SFN. ${ }^{\wedge} \mathrm{P}<0.001$ vs. FAT-1. BC, bladder cancer; FAT-1, FAT atypical cadherin 1; SFN, sulforaphane. 
A
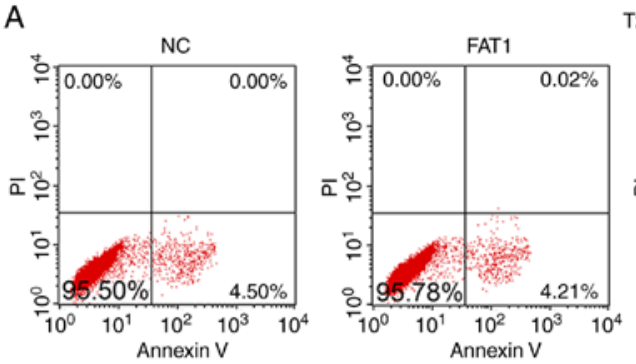

B

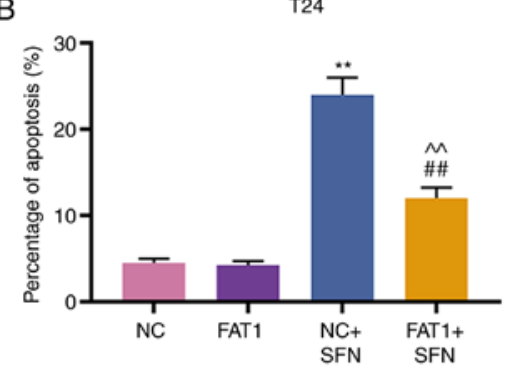

C
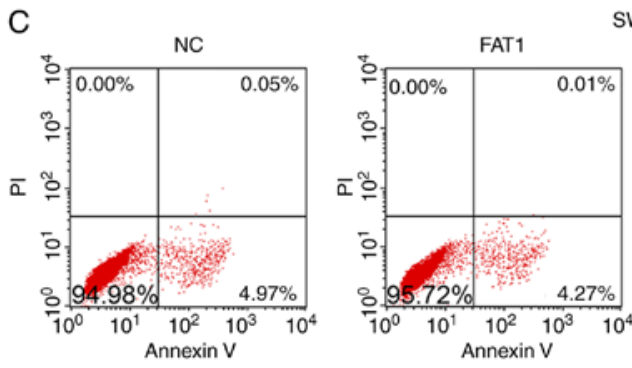

SW780
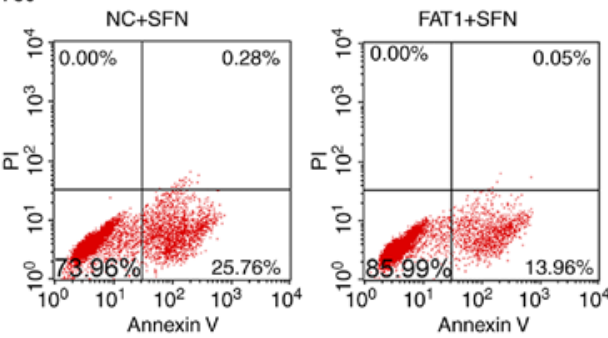

SW780
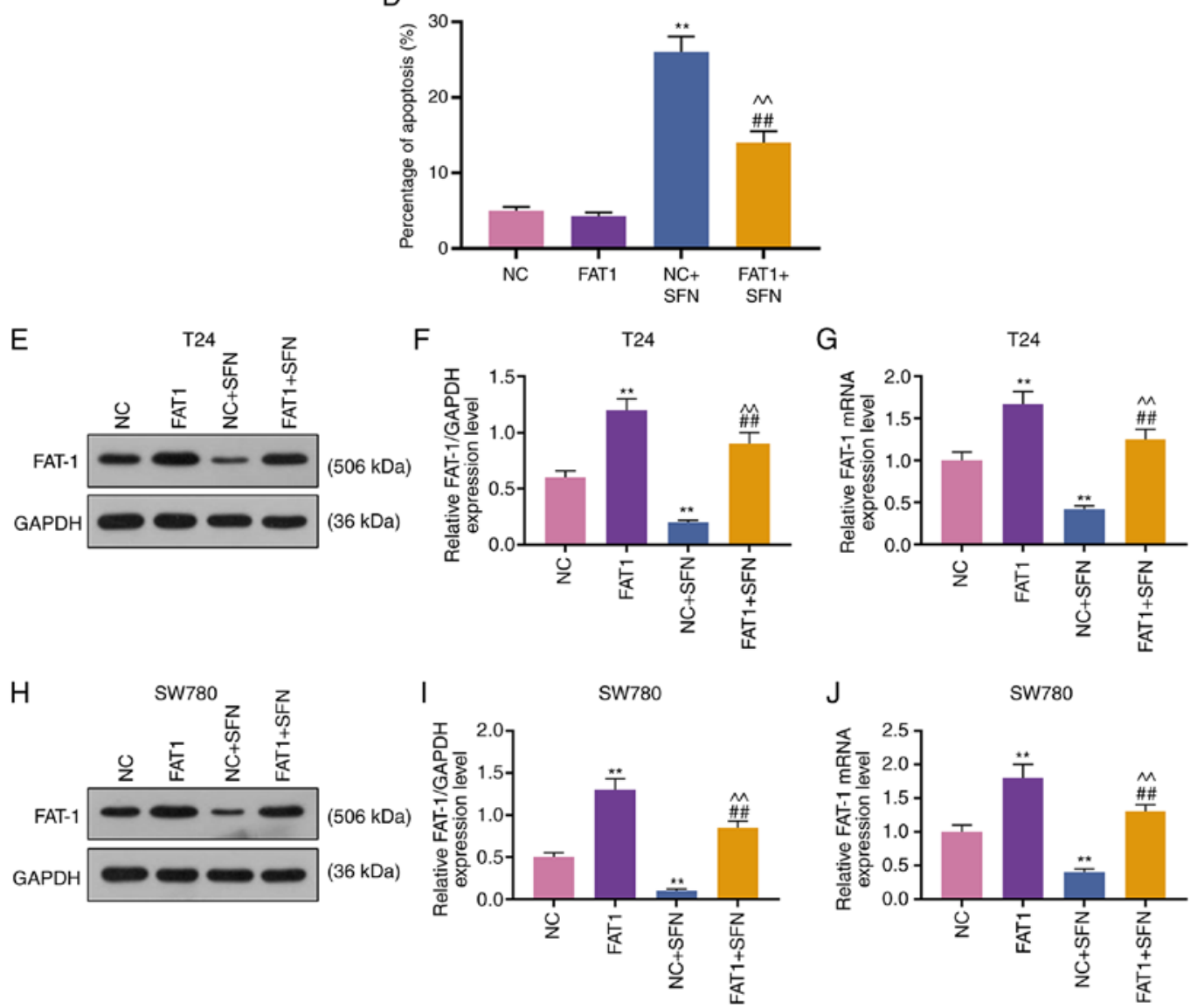

Figure 8. FAT-1 overexpression reverses the effects of SFN on the apoptosis of T24 and SW780 cells. (A-D) The apoptosis of T24 and SW780 cells was measured by flow cytometry. (E-J) Expression of FAT-1 was detected by western blot analysis and RT-qPCR, and was regulated by FAT-1 and SFN stimulation in T24 and SW780 cells. ${ }^{* *} \mathrm{P}<0.001$ vs. NC. ${ }^{\# \#} \mathrm{P}<0.001$ vs. NC $+\mathrm{SFN}$. ${ }^{\wedge} \mathrm{P}<0.001$ vs. FAT-1. BC, bladder cancer; FAT-1, FAT atypical cadherin $1 ;$ SFN, sulforaphane. 
such an effect is involved in mitochondrial dysfunction (17). Moreover, SFN has been found to regulate the metastasis and recurrence of BC by modulating EMT (33). Consistent with the findings of previous studies, the present study found that SFN inhibited the viability, and suppressed the migration and invasion of T24 and SW780 cells. Notably, it was also found that SFN decreased the expression of FAT1 in a dose-dependent manner. Further experiments found that BC cells exposed to SFN exhibited a reduced viability, migration and invasion, and these effects were enhanced by the silencing of FAT1 and were suppressed by FAT1 overexpression.

However, the molecular mechanisms of FAT1 in development of bladder cancer were not investigated in the present study. It has previously been demonstrated that FAT1 is involved in regulating the Hippo pathway $(34,35)$, the $\mathrm{Wnt} / \beta$-catenin pathway (36) and the MAPK/ERK pathway (37); however, whether these pathways are regulated in BC via FAT1 warrants further investigation. Moreover, the function of FAT1 in BC was not examined by an in vivo assay in the present study. It has been reported that FAT1-specific monoclonal antibody mAb198.3 can suppress the growth of colon cancer xenograft models; therefore, it can be developed as a potential drug for colorectal cancer (38). However, whether the FAT1-specific antibody can be applied to the treatment of BC remains unknown. Additionally, the mechanisms through which SFN regulates FAT1 remain unknown and warrant further investigation. A previous study demonstrated that SFN inhibits the invasion of glioblastoma cells by increasing the expression levels of E-cadherin, and decreasing the expression levels of MMP-2, MMP-9 and galectin-3 (39). Recently, a study found that SFN plays an anticancer role by targeting multiple molecules and pathways, such as Nrf2, histone deacetylases (HDACs), poly(ADP-ribose) polymerase (PARP), Bcl-2 family, MAPKs, hypoxia-inducible factor (HIF) $1 \alpha$ and NF- $\mathrm{kB}(8)$. However, the mechanisms underlying the regulation of FAT1 by SFN remain unclear. A limitation of the present study is that clinical data from a TCGA BC dataset were not compared. In addition, the association of other $\mathrm{BC}$ cadherins related to cell interactions or organization, and apoptosis related-factors were not investigated. Although the highest doses of SFN may not be achievable in vivo, drugs or approaches to tackle FAT-1 expression warrant further investigation.

In conclusion, the findings of the present study demonstrate that FAT1 is upregulated in BC tissues and cells. A high expression of FAT1 is predictive of a low 5-year survival rate of patients with BC. Moreover, SFN exerts a suppressive effect on the growth and metastasis of BC. Furthermore, the therapeutic effect of SFN on BC is possibly mediated by FAT1. Thus, the current findings provide a novel understanding of the role of SFN in BC.

\section{Acknowledgements}

Not applicable.

\section{Funding}

No funding was received.

\section{Availability of data and materials}

The datasets used and/or analyzed during the present study are available from the corresponding author on reasonable request.

\section{Authors' contributions}

FW and PL made substantial contributions to the conception and design of the study. PL and HA were involved in data acquisition, data analysis and interpretation, as well as in experiments including MTT, wound healing, and flow cytometry. FW and $\mathrm{YZ}$ were involved in the drafting of the manuscript or critically revising it for important intellectual content, as well as in experiments including RT-qPCR and western blot analysis. All authors read and approved the final manuscript. Agreement to be accountable for all aspects of the work in ensuring that questions related to the accuracy or integrity of the work are appropriately investigated and resolved.

\section{Ethics approval and consent to participate}

All procedures performed in studies involving human participants were in accordance with the ethical standards of the institutional and/or national research committee and with the 1964 Helsinki declaration and its later amendments or comparable ethical standards. The present study was reviewed and approved by the Committee For Ethical Review Of Research Involving Human Subjects at Shenzhen Hospital of Southern Medical University and all patients associated with the present study signed an informed consent.

\section{Patient consent for publication}

Not applicable.

\section{Competing interests}

The authors declare that they have no competing interests.

\section{References}

1. Antoni S, Ferlay J, Soerjomataram I, Znaor A, Jemal A and Bray F: Bladder cancer incidence and mortality: A global overview and recent trends. Eur Urol 71: 96-108, 2017.

2. Robertson AG, Kim J, Al-Ahmadie H, Bellmunt J, Guo G, Cherniack AD, Hinoue T, Laird PW, Hoadley KA, Akbani R, et al: comprehensive molecular characterization of muscle-invasive bladder cancer. Cell 171: 540-556.e25, 2017.

3. Kamat AM, Hahn NM, Efstathiou JA, Lerner SP, Malmström PU, Choi W, Guo CC, Lotan Y and Kassouf W: Bladder cancer. Lancet 388: 2796-2810, 2016.

4. Ebrahimi H,Amini E, Pishgar F, Moghaddam SS, Nabavizadeh B, Rostamabadi Y, Aminorroaya A, Fitzmaurice C, Farzadfar F, Nowroozi MR, et al: Global, regional and national burden of bladder cancer, 1990 to 2016: Results from the GBD study 2016. J Urol 201: 893-901, 2019.

5. Bai Y, Cui W, Xin Y, Miao X, Barati MT, Zhang C, Chen Q, Tan Y, Cui T, Zheng Y and Cai L: Prevention by sulforaphane of diabetic cardiomyopathy is associated with up-regulation of Nrf2 expression and transcription activation. J Mol Cell Cardiol 57: 82-95, 2013.

6. Wang G, Nie JH, Bao Y and Yang X: Sulforaphane rescues ethanol-suppressed angiogenesis through oxidative and endoplasmic reticulum stress in chick embryos. J Agric Food Chem 66: 9522-9533, 2018. 
7. Liu P, Atkinson SJ, Akbareian SE, Zhou Z, Munsterberg A, Robinson SD and Bao Y: Sulforaphane exerts anti-angiogenesis effects against hepatocellular carcinoma through inhibition of STAT3/HIF-1 $\alpha$ /VEGF signalling. Sci Rep 7: 12651, 2017.

8. Russo M, Spagnuolo C, Russo GL, Skalicka-Woźniak K, Daglia M, Sobarzo-Sánchez E, Nabavi SF and Nabavi SM: Nrf2 targeting by sulforaphane: A potential therapy for cancer treatment. Crit Rev Food Sci Nutr 58: 1391-1405, 2018.

9. McMahon $M$, Itoh $K$, Yamamoto $M$ and Hayes JD: Keap1-dependent proteasomal degradation of transcription factor Nrf 2 contributes to the negative regulation of antioxidant response element-driven gene expression. J Biol Chem 278: 21592-21600, 2003

10. Jeong WS, Keum YS, Chen C, Jain MR, Shen G, Kim JH, Li W and Kong AN: Differential expression and stability of endogenous nuclear factor E2-related factor 2 (Nrf2) by natural chemopreventive compounds in HepG2 human hepatoma cells. J Biochem Mol Biol 38: 167-176, 2005.

11. Choi S and Singh SV: Bax and Bak are required for apoptosis induction by sulforaphane, a cruciferous vegetable-derived cancer chemopreventive agent. Cancer Res 65: 2035-2043, 2005.

12. Yeh CT and Yen GC: Effect of sulforaphane on metallothionein expression and induction of apoptosis in human hepatoma HepG2 cells. Carcinogenesis 26: 2138-2148, 2005.

13. Hu R, Kim BR, Chen C, Hebbar V and Kong AN: The roles of JNK and apoptotic signaling pathways in PEITC-mediated responses in human HT-29 colon adenocarcinoma cells. Carcinogenesis 24 1361-1367, 2003.

14. Liu ZM, Chen GG, Ng EK, Leung WK, Sung JJ and Chung SC: Upregulation of heme oxygenase- 1 and p21 confers resistance to apoptosis in human gastric cancer cells. Oncogene 23: 503-513, 2004.

15. Gamet-Payrastre L, Lumeau S, Gasc N, Cassar G, Rollin P and Tulliez J: Selective cytostatic and cytotoxic effects of glucosinolates hydrolysis products on human colon cancer cells in vitro. Anticancer Drugs 9: 141-148, 1998.

16. Islam SS, Mokhtari RB, Akbari P, Hatina J, Yeger H and Farhat WA: Simultaneous targeting of bladder tumor growth survival, and epithelial-to-mesenchymal transition with a novel therapeutic combination of acetazolamide (AZ) and sulforaphane (SFN). Target Onco 11: 209-227, 2016.

17. Jo GH, Kim GY, Kim WJ, Park KY and Choi YH: Sulforaphane induces apoptosis in T24 human urinary bladder cancer cells through a reactive oxygen species-mediated mitochondrial pathway: the involvement of endoplasmic reticulum stress and the Nrf2 signaling pathway. Int J Oncol 45: 1497-1506, 2014.

18. Park HS, Han MH, Kim GY, Moon SK, Kim WJ, Hwang HJ, Park KY and Choi YH: Sulforaphane induces reactive oxygen species-mediated mitotic arrest and subsequent apoptosis in human bladder cancer 5637 cells. Food Chem Toxicol 64 $157-165,2014$

19. Wang S, Zhao X, Yang S, Chen B and Shi J: Salidroside alleviates high glucose-induced oxidative stress and extracellular matrix accumulation in rat glomerular mesangial cells by the TXNIP-NLRP3 inflammasome pathway. Chem Biol Interact 278: 48-53, 2017.

20. Srivastava C, Irshad K, Dikshit B, Chattopadhyay P, Sarkar C, Gupta DK, Sinha S and Chosdol K: FAT1 modulates EMT and stemness genes expression in hypoxic glioblastoma. Int $\mathrm{J}$ Cancer 142: 805-812, 2018.

21. Hu X, Zhai Y, Shi R, Qian Y, Cui H, Yang J, Bi Y, Yan T, Yang J, Ma Y, et al: FAT1 inhibits cell migration and invasion by affecting cellular mechanical properties in esophageal squamous cell carcinoma. Oncol Rep 39: 2136-2146, 2018.

22. Dikshit B, Irshad K, Madan E, Aggarwal N, Sarkar C, Chandra PS Gupta DK, Chattopadhyay P, Sinha S and Chosdol K: FAT1 acts as an upstream regulator of oncogenic and inflammatory pathways, via PDCD4, in glioma cells. Oncogene 32: 3798-3808, 2013.

23. Cazier JB, Rao SR, McLean CM, Walker AK, Wright BJ, Jaeger EE, Kartsonaki C, Marsden L, Yau C, Camps C, et al: Whole-genome sequencing of bladder cancers reveals somatic CDKN1A mutations and clinicopathological associations with mutation burden. Nat Commun 5: 3756, 2014.
24. Livak KJ and Schmittgen TD: Analysis of relative gene expression data using real-time quantitative PCR and the 2(-Delta Delta $\mathrm{C}(\mathrm{T})$ ) method. Methods 25: 402-408, 2001

25. Ranjit M, Motomura K, Ohka F, Wakabayashi T and Natsume A: Applicable advances in the molecular pathology of glioblastoma. Brain Tumor Pathol 32: 153-162, 2015.

26. Kan SF, Wang J and Sun GX: Sulforaphane regulates apoptosisand proliferation-related signaling pathways and synergizes with cisplatin to suppress human ovarian cancer. Int J Mol Med 42: 2447-2458, 2018

27. Choi YH: ROS-mediated activation of AMPK plays a critical role in sulforaphane-induced apoptosis and mitotic arrest in AGS human gastric cancer cells. Gen Physiol Biophys 37: 129-140, 2018.

28. Wang DX,Zou YJ,Zhuang XB, Chen SX, Lin Y,Li WL, Lin JJ and in ZQ: Sulforaphane suppresses EMT and metastasis in human lung cancer through miR-616-5p-mediated GSK3 $\beta / \beta$-catenin signaling pathways. Acta Pharmacol Sin 38: 241-251, 2017.

29. Lin SC, Lin LH, Yu SY, Kao SY, Chang KW, Cheng HW and Liu CJ: FAT1 somatic mutations in head and neck carcinoma are associated with tumor progression and survival. Carcinogenesis 39: 1320-1330, 2018.

30. Hayes TF, Benaich N, Goldie SJ, Sipilä K, Ames-Draycott A Cai W, Yin G and Watt FM: Integrative genomic and functional analysis of human oral squamous cell carcinoma cell lines reveals synergistic effects of FAT1 and CASP8 inactivation. Cancer Lett 383: 106-114, 2016.

31. Pileri P, Campagnoli S, Grandi A, Parri M, De Camilli E, Song C, Ganfini L, Lacombe A, Naldi I, Sarmientos P, et al: FAT1: A potential target for monoclonal antibody therapy in colon cancer. Br J Cancer 115: 40-51, 2016

32. Kranz D and Boutros M: A synthetic lethal screen identifies FAT1 as an antagonist of caspase-8 in extrinsic apoptosis. EMBO J 33: 181-197, 2014

33. Shan Y, Zhang L, Bao Y, Li B, He C, Gao M, Feng X, Xu W, Zhang $X$ and Wang S: Epithelial-mesenchymal transition, a novel target of sulforaphane via COX-2/MMP2, 9/Snail, ZEB1 and miR-200c/ZEB1 pathways in human bladder cancer cells. J Nutr Biochem 24: 1062-1069, 2013.

34. Ahmed AF, de Bock CE, Sontag E, Hondermarck H, Lincz LF and Thorne RF: FAT1 cadherin controls neuritogenesis during NTera2 cell differentiation. Biochem Biophys Res Commun 514: 625-631, 2019.

35. Martin D, Degese MS, Vitale-Cross L, Iglesias-Bartolome R, Valera JLC, Wang Z, Feng X, Yeerna H, Vadmal V, Moroishi T, et al: Assembly and activation of the Hippo signalome by FAT1 tumor suppressor. Nat Commun 9: 2372, 2018.

36. Alamoud KA and Kukuruzinska MA: Emerging insights into Wnt $/ \beta$-catenin signaling in head and neck cancer. J Dent Res 97: 665-673, 2018

37. Hu X, Zhai Y, Kong P, Cui H, Yan T, Yang J, Qian Y, Ma Y, Wang F, Li H, et al: FAT1 prevents epithelial mesenchymal transition (EMT) via MAPK/ERK signaling pathway in esophageal squamous cell cancer. Cancer Lett 397: 83-93, 2017.

38. Grifantini R, Taranta M, Gherardini L, Naldi I, Parri M, Grandi A, Giannetti A, Tombelli S, Lucarini G, Ricotti L, et al: Magnetically driven drug delivery systems improving targeted immunotherapy for colon-rectal cancer. J Control Release 280: 76-86, 2018.

39. Zhang Z, Li C, Shang L, Zhang Y, Zou R, Zhan Y and Bi B Sulforaphane induces apoptosis and inhibits invasion in U251MG glioblastoma cells. Springerplus 5: 235, 2016

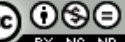

This work is licensed under a Creative Common Attribution-NonCommercial-NoDerivatives 4.0 International (CC BY-NC-ND 4.0) License. 